\title{
TOTAL REPLACEMENT OF THE MITRAL APPARATUS WITH A STENTLESS, CHORDALLY SUPPORTED MITRAL VALVE ALLOGRAFT: AN EXPERIMENTAL STUDY
}

Herbert Vetter, MD ${ }^{\mathbf{a}}$

Andreas Nerlich, $\mathrm{MD}^{\mathrm{b}}$

Ulrich Welsch, MD ${ }^{\mathrm{c}}$

Kangxiong Liao, MD $^{\mathrm{d}}$

Andreas Dagge, MS ${ }^{\mathrm{a}}$

Christine Strenkert, MS

Bruno Reichart, $\mathrm{MD}^{\mathrm{a}}$
Mitral valves, including the papillary muscles, were harvested from freshly slaughtered sheep and implanted in 10 recipient growing sheep. A strip of ovine pericardium was used to reinforce the anulus and a patch of expanded polytetrafluoroethylene was used to cover the donor papillary muscle. In four valves the natural chordae tendineae at the anterior cusp were supported by two pairs of 5-0 expanded polytetrafluoroethylene sutures. At the beginning of the experiment two animals died early of valve incompetence. Another animal had to be put to death because of paraplegia after extracorporeal circulation and one died on postoperative day 41 of endocarditis. Six sheep were electively put to death, five after $153 \pm 8$ days and one after 43 days. At the time of follow-up, a complete hemodynamic study including echocardiography and stress testing was performed. Heart rate at rest was $91 \pm 14$ beats/min, left ventricular systolic pressure $96 \pm 20 \mathrm{~mm} \mathrm{Hg}$, left ventricular end-diastolic pressure $11 \pm 5 \mathrm{~mm} \mathrm{Hg}$, cardiac output $2.04 \pm 0.40 \mathrm{~L} / \mathrm{min}$, and the mean transvalvular pressure gradient was $4.9 \pm 2.8 \mathrm{~mm} \mathrm{Hg}$ as measured by cardiac catheterization. Echocardiography showed excellent movement of all valve components. However, minor regurgitation was evident in one case. Gross morphologic characteristics showed good healing at the anulus and host papillary muscle; in one case there was a rupture of one small first-order chorda. On radiography no signs of calcification were evident. Light microscopy revealed minor to moderate collagen degeneration in all valve components. However, on electron microscopy the presence of numerous fibroblasts within the long-term implants indicated the biosynthesis of new collagen. In summary, allograft mitral valve replacement seems to be a promising procedure if the chordae tendineae are reinforced by expanded polytetrafluoroethylene sutures. (J THORAC CARDIOvaSC SuRG 1996;111:595-604)
$P$ reservation of the mitral valve should be preferred to avoid mitral valve replacement with mechanical or bioprosthetic valves. Left ventricular function improves if the continuity between the papillary muscle and leaflet is preserved in such operations. ${ }^{1,2}$

From the Departments of Cardiac Surgery, ${ }^{\mathrm{a}}$ Pathology, ${ }^{\mathrm{b}}$ and Anatomy, ${ }^{\mathrm{c}}$ Ludwig-Maximilians University, Munich, Germany, and the Cardiothoracic Research Laboratory, ${ }^{\mathrm{d}}$ The Albert Einstein College of Medicine of Yeshiva University, Bronx, N.Y.

Supported by a grant from the Deutsche Stiftung für Herzforschung, Frankfurt, Germany.

Received for publication Dec. 28, 1994; accepted for publication May 31, 1995.

Address for reprints: Herbert Vetter, MD, Department of Cardiac Surgery, University of Munich, Herzklinik Augustinum, Wolkerweg 16, 81375 Munich, Germany.

Copyright (C) 1996 by Mosby-Year Book, Inc.

0022-5223/96 \$5.00+0 12/1/66607
However, in only $20 \%$ to $30 \%$ of patients undergoing mitral valve operations can a valve reconstruction be performed. As in aortic valve operations, cryopreserved allografts might be expected to be the ideal substitutes in mitral valve replacement. Because of the complexity of the mitral valve apparatus (anulus, leaflets, chordae tendineae, papillary muscles), replacement of the diseased valve with a mitral allograft has been attempted previously in only a few patients, and with limited long-term success. ${ }^{3,4}$ Rupture of the chordae tendineae was the principal cause of mitral incompetence.

An experimental study was designed to evaluate the in vivo function and the long-term durability of a transplanted allograft mitral valve in a growing sheep model. For the purpose of reinforcing the natural chordae tendineae of the allograft, artificial chordae made from expanded polytetrafluoroethylene (ePTFE) su- 


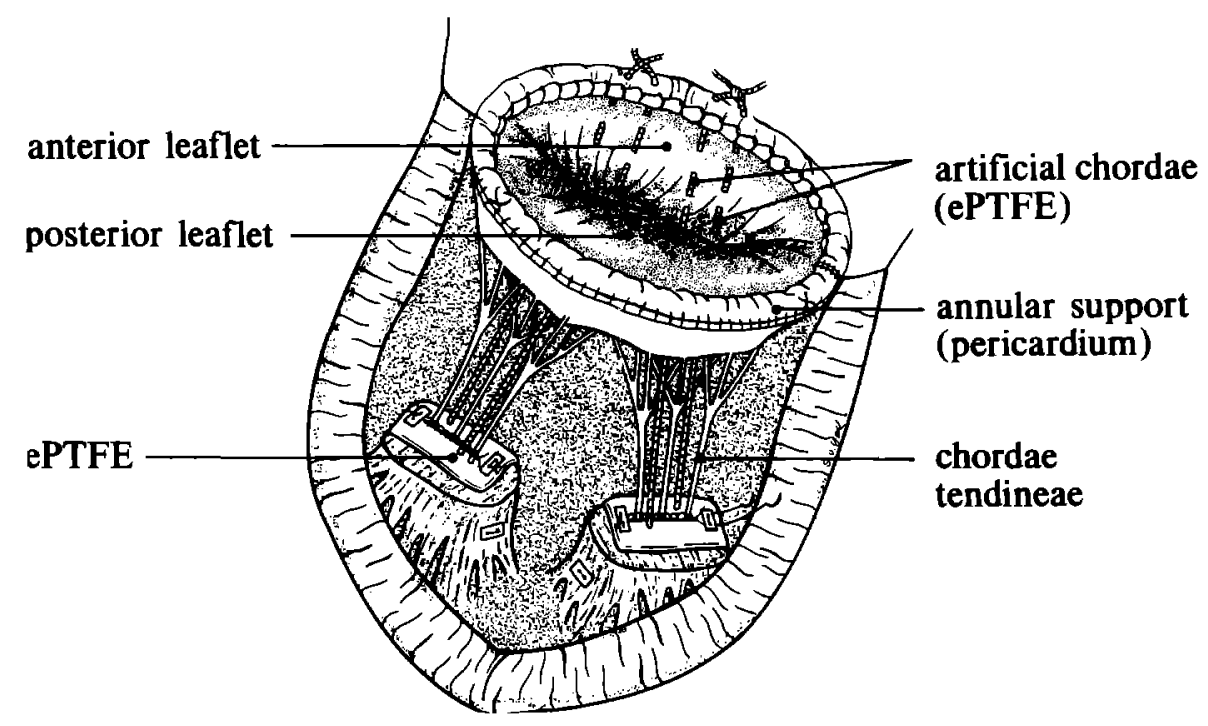

Fig. 1. Stentless allograft mitral implant including artificial chordae of ePTFE suture at the anterior leaflet.

tures were applied to the mitral implant. Such ePTFE chordae were first used experimentally in $1984^{5}$ and have since been applied successfully as chordal substitutes in many patients. ${ }^{6-8}$

\section{Material and methods}

Allograft preparation. Complete mitral valves, including the mitral anulus, the papillary muscles, and the chordae tendineae, were excised from the hearts of freshly slaughtered sheep weighing between 30 and $35 \mathrm{~kg}$. A strip of untreated ovine pericardium from the same donor sheep was used to reinforce the natural valve anulus (Fig. 1). A patch, $0.4 \mathrm{~mm}$ thick, consisting of ePTFE, ${ }^{*}$ was used to cover the tips of the papillary muscle of the donor graft. This patch was sutured to the truncated papillary muscles with a 5-0 ePTFE suture. In four implants the same suture was woven through the anterior leaflet and knotted at the annular site to reinforce the natural chordae tendineae. The internal diameter of the donor mitral valves ranged between 25 and 29 $\mathrm{mm}$. For the in vivo studies, allografts of $23 \mathrm{~mm}$ and $25 \mathrm{~mm}$ internal diameter were manufactured to match the size of the recipient mitral anulus. Therefore the anulus of the donor mitral valve had to be reduced.

Several species of microorganisms were detected on microbiologic examination of the harvested valves. Listed by decreasing frequency of occurrence, they were Staphylococcus epidermidis, Escherichia coli, Corynebacterium sp., Bacteroides fragilis, Candida blastomyces, and Acinetobacter. After this examination, the stentless implant was rinsed with Ringer's solution and incubated for 24 hours at $4^{\circ} \mathrm{C}$ in an antibiotic solution containing a mixture of ciprofloxacin, amikacin, vancomycin, metronidazol, and amphotericin B. Valves were stored at $4^{\circ} \mathrm{C}$ (Earle medium 199) and implanted within 2 weeks. Swabs were

\footnotetext{
${ }^{*}$ Gore-Tex cardiovascular patch, registered trademark of W. L. Gore \& Associates, Inc., Elkton, Md.
}

taken frequently for microbiologic examination. Only sterile valves were used for long-term animal studies.

Operative technique. Implantation of the stentless allograft mitral valves was performed in 10 female growing sheep (Orne Biotechnologies Inc., New Hope, Pa.) with a mean body weight of 22 to $26 \mathrm{~kg}$. The animals were anesthetized with pentobarbital $2 \mathrm{mg} / \mathrm{kg}$, intubated, and then supported with a respirator; anesthesia was maintained by administration of an oxygen-nitrous oxide mixture and halothane. Heart rate was monitored by a standard electrocardiogram. The heart was exposed through a left thoracotomy in the fourth intercostal space. After systemic heparinization $(1 \mathrm{mg} / \mathrm{kg})$, cardiopulmonary bypass was established by cannulation of the left femoral artery for arterial perfusion and cannulation of the right atrial appendage for venous return. Mitral valve transplantation was performed with the heart beating; no cardioplegic solution was used. A left atriotomy was carried out and the native mitral valve was completely excised, including the tips of the papillary muscles. After sizing of the annular ring, the appropriate allograft implant was chosen. Two mattress sutures (4-0 polypropylene) armed with Teflon pledgets were placed at the site of the host's anterior and posterior papillary muscles and then returned through the ePTFE patch of the implant. Tying down these four sutures drew the mitral implant into place. The anulus was sewn with a continuous 5-0 polypropylene suture. Valve competence was tested by injecting saline solution into the left ventricle. Air was evacuated from the beating heart and the atriotomy was closed. After removal of the perfusion cannulas, the heparin effect was reversed with protamine sulfate and the chest was closed. Morphine was given intramuscularly to relieve postoperative pain. For postoperative infectious prophylaxis, gentamicin ( $2 \mathrm{mg} / \mathrm{kg}$ per day) and cefamandole $(75 \mathrm{mg} / \mathrm{kg}$ per day) were given intramuscularly for 10 days.

All animals received humane care in compliance with the "Principles of Laboratory Animal Care" formulated 
by the National Society for Medical Research and the "Guide for the Care and Use of Laboratory Animals" prepared by the Institute of Laboratory Animal Resources and published by the National Institutes of Health (NIH Publication No. 86-23, revised 1985).

Long-term follow-up. The sheep were frequently examined for signs of heart failure (breathing rate, ascites, heart murmur) and maintained at the animal institute until they were electively put to death. At that time the sheep were anesthetized as described earlier. A Swan-Ganz catheter (Baxter Healthcare Corp. Edwards Div., Santa Ana, Calif.) was introduced through the right jugular vein for measurement of central venous pressure, pulmonary artery pressure, pulmonary artery wedge pressure, and cardiac output. Aortic pressure was obtained by catheterization of the left carotid artery, and left ventricular pressure and left ventricular end-diastolic pressure were measured via a Mikro-Tip manometer (Millar Instruments Inc., Houston, Tex.) placed in the left ventricular cavity through the right carotid artery. Left atrial pressure was obtained by cannulation of a pulmonary vein. Measurements were taken at rest and after stress load with a continuous infusion of norepinephrine, $1 \mu \mathrm{g} / \mathrm{kg}$ per minute. The effective orifice area was calculated with a modified Gorlin formula. All parameters are given as means \pm standard deviation.

In addition, epicardial echochardiography and pulsed Doppler studies were performed (model 77020A, 2.5 $\mathrm{MHz}$ transducer, Hewlett-Packard Company, Andover, Mass.) before the final hemodynamic studies. Experiments were terminated by intravenous injection of potassium chloride. The hearts were dissected and macroscopically examined. Roentgenograms (mammography technique) of all specimens were taken at $26 \mathrm{keV} / 6.3 \mathrm{~mA}$ to determine calcific deposits.

Areas of interest of the specimen were fixed in $4 \%$ formaldehyde and processed for histologic examination with a light microscope. Samples were stained with hematoxylineosin and elastica-van Gieson stains. For electron examination with an microscope, small segments of the specimen were immediately fixed in $2.5 \%$ glutaraldehyde buffered with cacodylate $0.1 \mathrm{~mol} / \mathrm{L}$, pH 7.4, postfixed with $1 \%$ osmium tetroxide in the same buffer, then dehydrated in an alcohol series. Transmission electron microscopy was performed with a Zeiss 900 electron microscope (Zeiss, Jena, Germany). For scanning electron microscopy, the specimens were critical point dried with carbon dioxide, mounted, coated with gold-palladium, and observed with a Jeol T20 scanning electron microscope (Jeol, Peadbody, Mass.).

\section{Results}

All 10 animals survived the surgical procedure. At the beginning of the study two sheep died early on the second and ninth postoperative days, respectively, because of valve incompetence. The reason in the first case was surgically related (twisting of a papillary muscle). Rupture of a central chorda at the anterior leaflet was identified at autopsy in the second case; in addition, an atrial septal defect had been closed by direct suture at the time of allograft implantation in this sheep. One animal died of endocarditis 7 weeks after mitral valve implantation. Another sheep had paraplegia of the back legs after the surgical procedure. This animal was anesthetized and catheter and echocardiographic studies were performed, which showed no signs of mitral incompetence or stenosis. The animal was put to death and the mitral implant was found to be intact. The result was that six sheep were able to be put to death electively, five sheep after $158 \pm 8$ days and one after only 43 days. The mean body weight at the time of death was $32.0 \pm 2.8 \mathrm{~kg}$. A $23 \mathrm{~mm}$ valve was implanted in five animals and a 25 $\mathrm{mm}$ valve in one.

Hemodynamic study. At follow-up the average heart rate at rest was $91 \pm 14$ beats/min, increasing during exercise to $131 \pm 25$ beats/min. Left ventricular pressure rose from $96 \pm 20$ to $133 \pm 38 \mathrm{~mm} \mathrm{Hg}$; left ventricular end-diastolic pressure was $11 \pm 5 \mathrm{~mm} \mathrm{Hg}$ at rest and $10 \pm 2 \mathrm{~mm} \mathrm{Hg}$ during stress test. The average cardiac output increased from $2.04 \pm 0.50$ $\mathrm{L} / \mathrm{min}$ to $3.38 \pm 1.09 \mathrm{~L} / \mathrm{min}$. The mean mitral valve gradient was $4.9 \pm 2.8 \mathrm{~mm} \mathrm{Hg}$ on average at baseline measurements and rose to $8.1 \pm 4.5 \mathrm{~mm} \mathrm{Hg}$ during norepinephrine infusion. Calculated effective orifice area was $1.01 \pm 0.59 \mathrm{~cm}^{2}$ versus $1.39 \pm 0.60 \mathrm{~cm}^{2}$.

Echocardiography. Two-dimensional echocardiography of the left ventricular short axis showed full simultaneous opening of the anterior and posterior cusps throughout the cardiac cycle. The long-axis view revealed a correct anatomic valve position and good attachment of the subvalvular apparatus with chordae tendineae under continuous tension. Epicardial twodimensional echocardiography at the end of follow-up revealed competent valves with minor regurgitation only in one valve and unchanged marginal overlapping (Fig. 2, $A$ and $B$ ). Complete echocardiographic data have been published recently. ${ }^{9}$

Gross morphologic features (Table 1). All mitral allografts showed good healing of the anulus and of the papillary muscle (Figs. 3 and 4). The leaflets and the natural chordae were pliable without signs of calcification. However, in one specimen a first-order chorda (free-edge chorda) was thinned and in another case a first-order chorda had ruptured at the anterior leaflet. The last valve was the one that showed minor regurgitation (grade I) on echocardiography. Neither valve was chordally supported. No chordal ruptures occurred at the papillary muscles. In the four valves in which artificial ePTFE chordae were added, all natural chordae were intact. In three of these valves the ePTFE chordae were covered by a thin smooth tissue; in the fourth valve, however, the artificial chordae were thinned and lacked flexibility at the papillary muscle site, and one single suture was ruptured. The ePTFE patches at the papillary muscle sites were all 

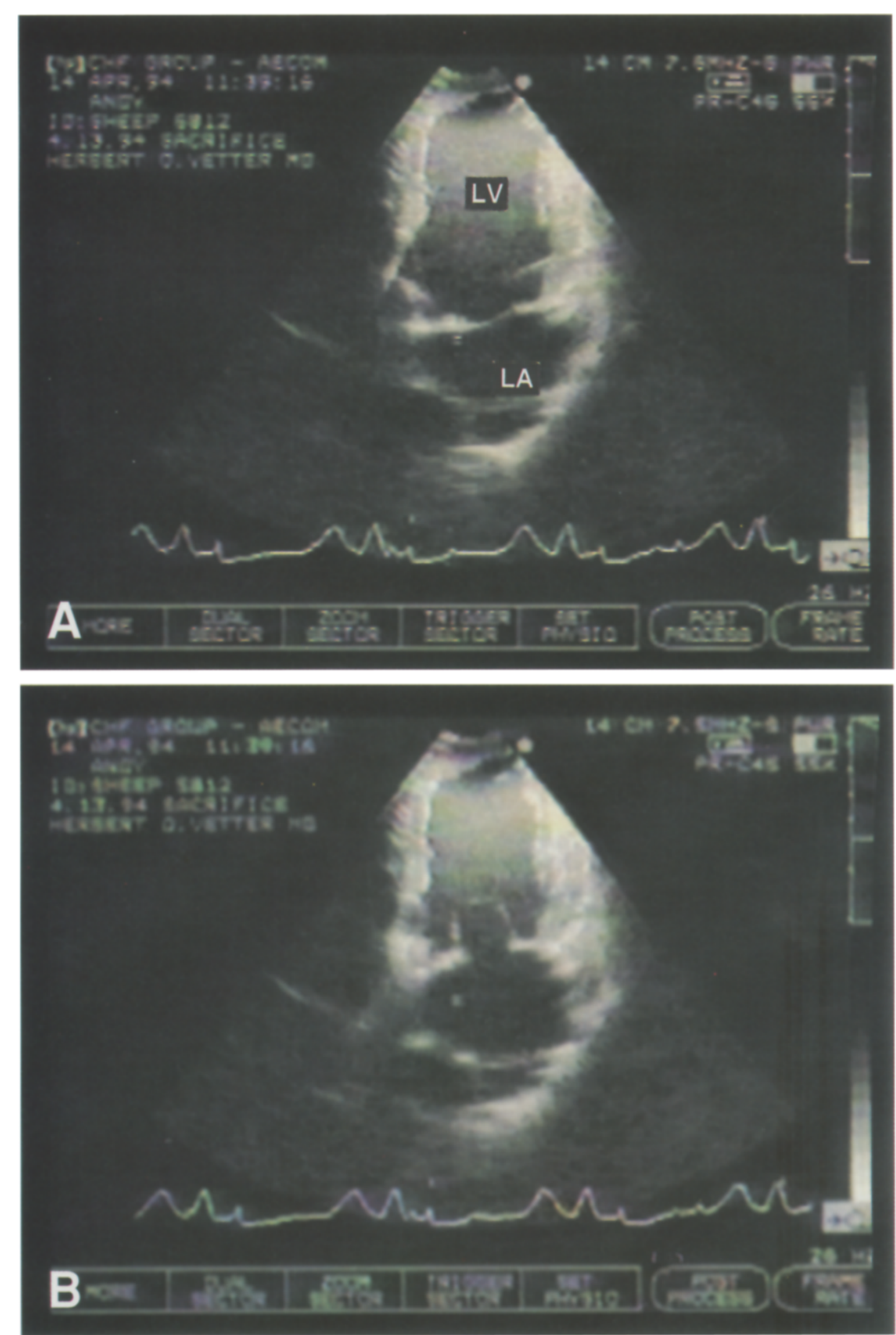

Fig. 2. Two-dimensional echocardiogram (left ventricular long axis) during systole (A) and diastole (B) of a stentless, chordally supported allograft mitral valve 154 days after implantation. $L A$, Left atrium; $L V$, left ventricle.

covered by fibrous tissue and had healed well to the host tissue.

Radiographic examination of the explanted valves revealed no significant signs of calcification within the anulus, the leaflets, and the chordae tendineae (see Table I, Fig. 5). However, the artificial, ePTFE chordae were calcified in one case on $\mathrm{x}$-ray examination. 
Table I. Gross morphologic and histologic characteristics of explanted stentless mitral allografts

\begin{tabular}{|c|c|c|c|c|c|}
\hline & Anulus & Leaflets & Chordae tendineae & ePTFE chordae* & Papillary muscle \\
\hline Gross morphology & $\begin{array}{l}\text { Good healing, } \\
\text { autologous } \\
\text { pericardium } \\
\text { flexible, no } \\
\text { fibrous } \\
\text { overgrowth }\end{array}$ & $\begin{array}{l}\text { Natural pliability, } \\
\text { no tissue } \\
\text { overgrowth }\end{array}$ & $\begin{array}{l}\text { Pliable, normal } \\
\text { appearance }(n=4) ; \\
\text { first-order chordae } \\
\text { thinned }(n=1) \\
\text { and ruptured }(n=1) \\
\text { at leaflet site; } \\
\text { good healing at } \\
\text { papillary muscle site }\end{array}$ & $\begin{array}{l}\text { Pliable ( } n=3) \\
\text { fibrous overgrowth; } \\
\text { calcification } \\
\text { (n=1, with } \\
\text { rupture of a } \\
\text { single suture) }\end{array}$ & $\begin{array}{l}\text { Good healing, } \\
\text { fibrous tissue } \\
\text { overgrowth, } \\
\text { ePTFE patch } \\
\text { covered by } \\
\text { fibrous tissue }\end{array}$ \\
\hline $\begin{array}{l}\text { Radiographic } \\
\text { calcification }\end{array}$ & $\begin{array}{l}\text { None }(n=4) \\
\quad \text { minimal }(n=2)\end{array}$ & $\begin{array}{l}\text { None }(n=5) \\
\quad \text { minimal }(n=1)\end{array}$ & None & $\begin{array}{l}\text { None }(n=3) \\
\quad \text { minimal }(n=1)\end{array}$ & $\begin{array}{l}\text { None }(n=4) \\
\quad \text { minimal }(n=2)\end{array}$ \\
\hline Light microscopy & $\begin{array}{l}\text { Good healing, } \\
\text { degeneration } \\
\text { of donor } \\
\text { pericardium, } \\
\text { moderate } \\
\text { collagen } \\
\text { degeneration }\end{array}$ & $\begin{array}{l}\text { Fibrous layer: } \\
\text { minimal }(n=4) \\
\text { Collagen } \\
\text { degeneration: } \\
\text { minimal }(n=2) ; \\
\text { moderate }(n=4) ; \\
\text { Chronic } \\
\text { inflammatory } \\
\text { reaction: none } \\
(n=1) ; \text { minimal } \\
(n=2) ; \text { moderate } \\
(n=3)\end{array}$ & $\begin{array}{l}\text { Thin superficial } \\
\text { fibrous layer; } \\
\text { isolated macrophages } \\
\text { Collagen degeneration: } \\
\text { minimal }(n=6) \\
\text { No inflammatory reaction }\end{array}$ & Not done & $\begin{array}{l}\text { Fibrosis: moderate } \\
\quad(n=3) \text {; severe } \\
(n=3) \\
\text { Fibrosis of the donor } \\
\text { papillary muscle, } \\
\text { chronic inflammatory } \\
\text { infiltration, foreign } \\
\text { body reaction } \\
\text { (PTFE) }\end{array}$ \\
\hline
\end{tabular}

*Implanted in four animals, four chordae each.

Histologic results. The histologic results revealed by light microscopy are summarized in Table I. Good healing of the allograft both to the anulus and to the papillary muscle was found (Fig. 6). A thin fibrous overgrowth was detected at the site of the anulus, the leaflets, and the natural chordae tendineae. The ePTFE patch was completely covered by fibrous tissue in all cases. Necrosis of the donor papillary muscle and replacement by scar tissue were evident (Fig. 6, $B$ ). In two valves the atrial myocardium of the donor was fibrotic at the allograft anulus. A chronic inflammatory reaction (macrophages, granulocytes) was seen in two explanted valves within the leaflets at the site of annular attachment. This reaction was more evident within the papillary muscles. However, the chordae tendineae showed no signs of an inflammatory infiltration.

Transmission electron microscopy revealed collagenous structures ranging from well-organized fibrils to loose bundle formation to areas of complete lysis. Occasional electron dense, presumably calcareous, deposits were found to be attached to the collagen fibrils (Fig. 7). Elastic fibers with broad peripheral zones of microfibrils have been observed frequently. Numerous active fibroblasts could be found within the leaflets and the chordae tendineae. These fibroblasts showed a well-developed rough endoplasmic reticulum, a euchromatin-rich nucleus, and numerous extensions. Several fibroblasts were surrounded by a fairly dense layer of collagen fibrils (Fig. 8). A complete denuda- tion of the cardial endothelium was detected by scanning electron microscopy. Both leaflets and chordae tendineae were covered by a regularly shaped layer of fibrous tissue. The ePTFE chordae were almost completely covered by fibrous tissue. Occasional fibroblasts could be detected.

\section{Discussion}

Experimental studies are the basis for significant new surgical methods before they are applied in patients. During this study, case reports on the use of homograft mitral valves in patients were published by other investigators. In 1993, Pomar and Mestres ${ }^{10}$ reported on tricuspid valve replacement with a mitral homograft. Acar and associates ${ }^{11}$ published the use of a cryopreserved homograft for mitral valve replacement in 1994. Despite the report on chordal rupture during the follow-up by Sievers and coworkers, ${ }^{4}$ no "design" changes were suggested from these investigators. Partial replacement of the anterior mitral cusp with cryopreserved allografts was successfully performed in sheep by Revuelta's group. ${ }^{12}$ A stentless and chordally supported bovine pericardial mitral prosthesis underwent successful experimental testing by Liao, Wuu, and Frater. ${ }^{13}$

In our experimental design we applied some significant modifications to the native allograft mitral valve to reinforce the anulus, the chordae tendineae, and the papillary muscles. In preliminary experiments, we used "nonmodified" mitral homografts in a series of sheep. 


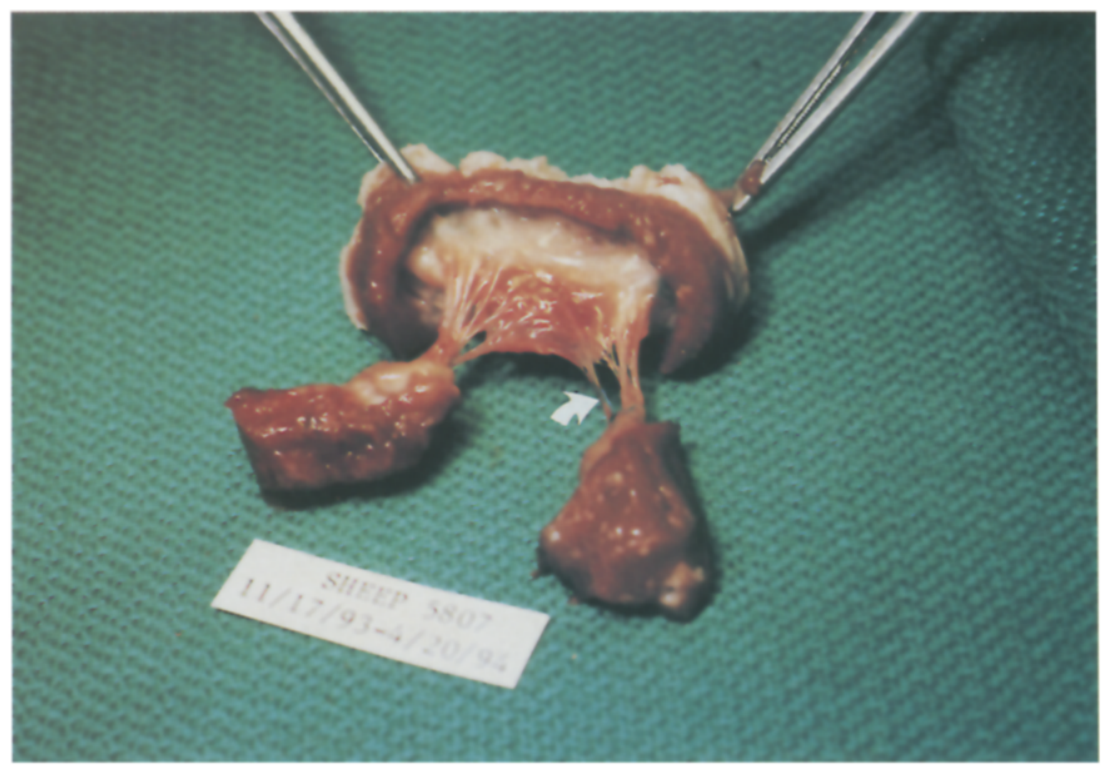

Fig. 3. Explanted mitral valve allograft 156 days after implantation. Good healing at the anulus and at the papillary muscle is evident. Cusps and chordae tendineae are pliable without signs of fibrosis. However, some chordae tendineae appear thinned (arrow). No artificial chordae had been used in this mitral implant.

Because of leaflet rupture at the annular side and tearing of chordae at the site of the papillary muscles, resulting in early death, we did modify the homograft valve. No late deaths occurred during follow-up as a result of failure of any of the components of the mitral apparatus comprising the allograft implant. Reinforcement of the mitral anulus with autologous pericardium had a purpose, because the mitral valve of sheep is rather fragile. Because the donor sheep were heavier (about $35 \mathrm{~kg}$ ) than the recipient sheep (22 to $26 \mathrm{~kg}$ ), we had to reduce the anulus of the donor mitral valve to an internal diameter of $23 \mathrm{~mm}$ and $25 \mathrm{~mm}$ to facilitate implantation into the recipient sheep. This allowed the appositional area of the mitral allograft implant to increase, allowing more flexibility in valve adjustment during the implant procedure. In some cases the donor papillary muscles had to be sewn along side the remaining recipient papillary muscles to avoid prolapse. Therefore the whole mitral implant was rotated 5 to $10 \mathrm{~mm}$.

The finding of thinned chordae tendineae among normally appearing chordae might indicate different areas of stress of implanted allografts. Early clinical results of the use of a stentless porcine mitral valve substitute introduced by Vrandecic and colleagues ${ }^{14}$ in 1992 revealed chordal rupture as a major problem. Morea and associates ${ }^{15}$ reported on three early valve failures from rupture of first-order chordae in a group of seven patients. The use of ePTFE suture as a substitute for chordae tendineae has been investigated experimentally ${ }^{5}$ and recently advocated clinically in a 7-year follow-up of 106 patients by Zussa and coworkers. ${ }^{8}$ In our study, however, in one case we found calcification of the ePTFE sutures. The preimplantation treatment and storage of the stentless allograft mitral implant in our study might have had a negative effect on the artificial material, which caused a rupture in one case. The histologic investigation could not clarify the mechanism of the rupture of the ePTFE chorda. Nevertheless, we are convinced that the use of ePTFE chordae is the most suitable approach for reinforcement and replacement of chordae tendineae at present.

Good healing in the recipient, partly the result of foreign-body reaction to the ePTFE patch, was found at the papillary muscle site. The vigorous fibrous overgrowth including the origin of the natural chordae tendineae was able to strengthen that "weak" site. As a result, no chordal rupture was detected at the site of the papillary muscles at follow-up.

The histologic changes in the explanted allografts showed a minor to moderate degree of collagen degeneration. However, all valves were still pliable without evidence of major calcification, although occasional small calcifications could be seen. Valve function was not impaired by these changes. The most significant finding of this experimental study was the appearance of active fibroblasts within the transplanted allograft tissue. These fibroblasts were observed more frequently near the tissue surface. 


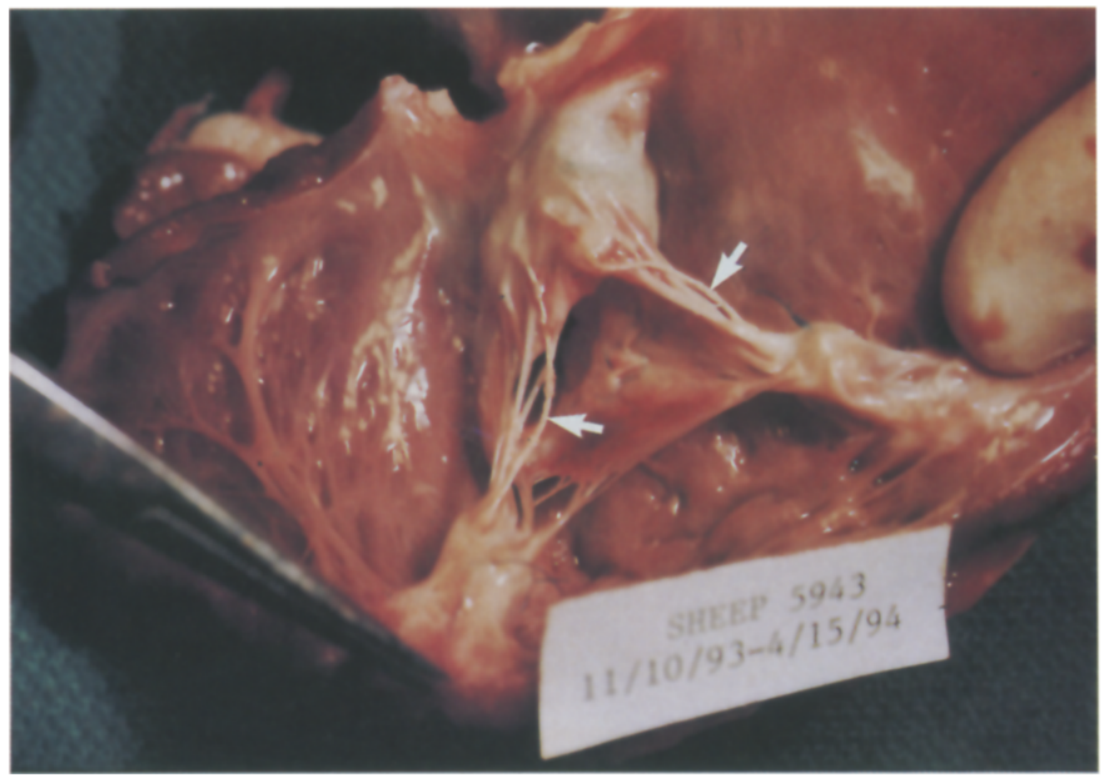

Fig. 4. Specimen explanted after 154 days. All valve components are well preserved and pliable. The artificial ePTFE suture chordae showed good healing to the anterior leaflet, and they were able to protect the natural chordae tendineae from thinning and from rupture. Arrow, ePTFE suture.

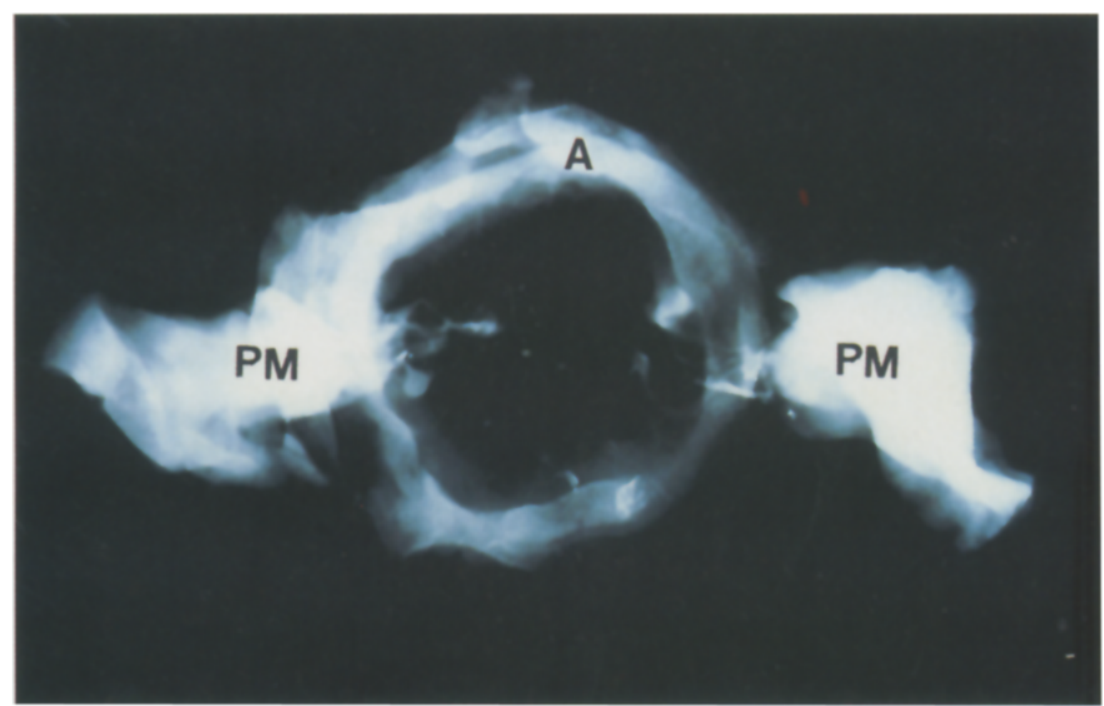

Fig. 5. Radiograph of a stentless mitral allograft implanted for 158 days showing no signs of calcification in the area of leaflets and chordae tendineae. $A$, Mitral valve anulus; $P M$, papillary muscle.

These cells clearly originate from the host and invade the donor tissue. The packed, relatively thin collagen fibrils (immature fibrils?) surrounding many of these active fibroblasts suggest production of new collagen by host-mediated cells. In fact, this has always been the hope with homografts but, to our knowledge, has not yet been seen with homograft aortic valves. Turnover and resorption of collagen are essential for efficient wound healing and for the maintenance of structural integrity in load-bearing and pressure-bearing organ systems. ${ }^{16}$ In some areas of the valvular tissue indications for the beginning of calcification were found (Fig. 7). However, in the growing sheep model 5 to 6 months after implantation, we would expect rather more severe calcific changes as seen after implantation of bioprosthetic xenografts. ${ }^{17,18}$

When glycerol-treated autologous pericardium was used for chordal replacement in sheep, not only was 

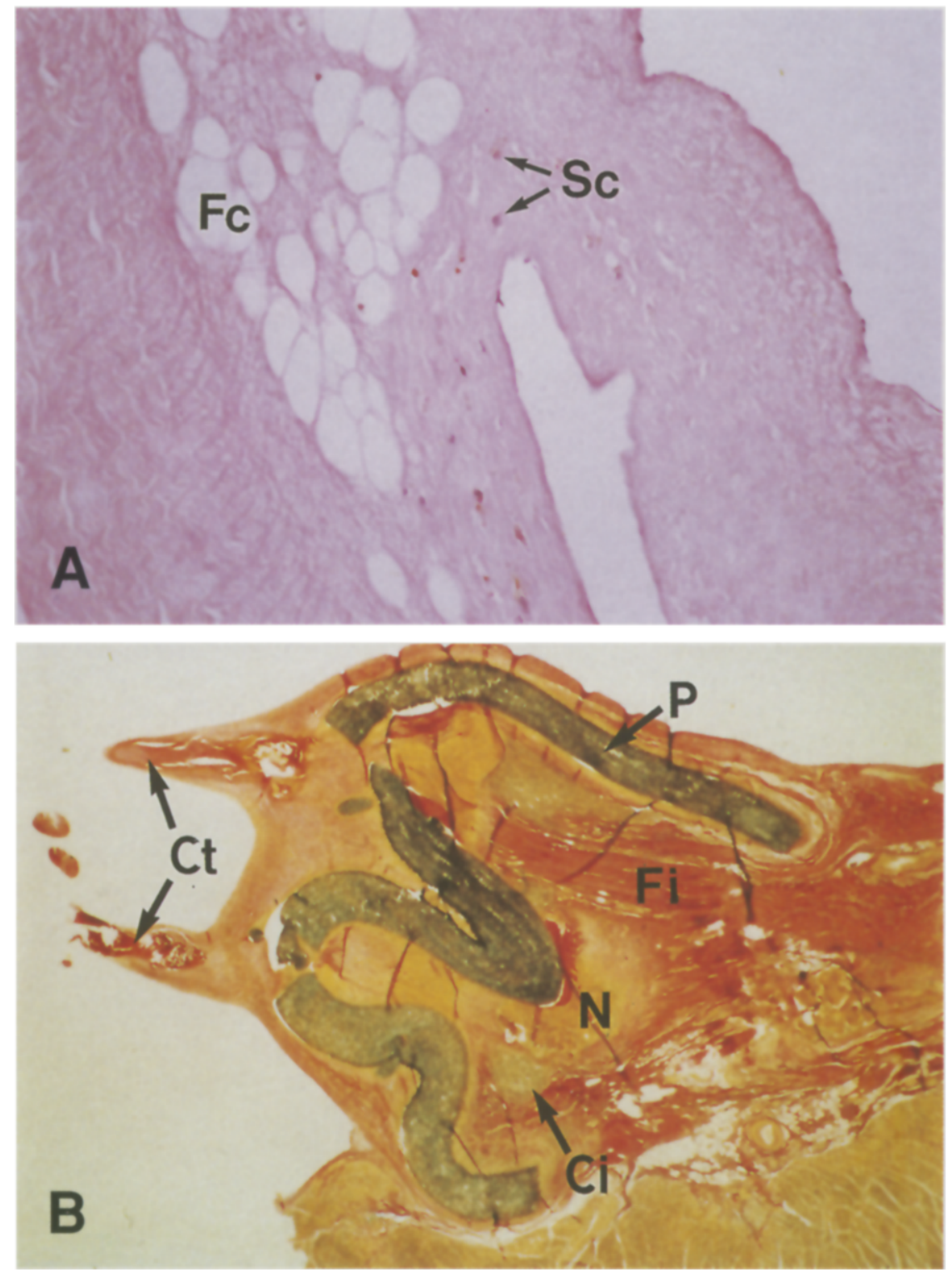

Fig. 6. Light microscopy of a specimen implanted for 158 days. A, Histologic aspect of the transplanted valve with interspersed atrial fat cells $(F c)$ and occasional residual fibroblactic stroma cells $(S c)$. No inflammatory infiltration is apparent. (Hematoxylin-eosin stain; original magnification $\times 30$.) B, Histologic section through the papillary muscle. Note the ePTFE patch $(P)$, focal necrosis $(N)$ of the donor muscle, fibrosis ( $F i$ ), and isolated areas of chronic inflammatory infiltration $(\mathrm{Ci})$. $\mathrm{Ct}$, chordae tendineae. (Elastica-van Gieson stain; original magnification $\times 20$.)

the implanted pericardium covered by host tissue, but also the host tissue was remodeled, apparently in response to functional requirements of the implant. ${ }^{19}$ In our experience, the growing sheep model seems most suitable for the investigation of new cardiac bioprostheses. Implantation periods of 5 to 6 months are sufficient for evaluation of valve behavior and for detection of long-term morphologic changes.

Because we were not able to harvest sterile donor valves, antibiotic sterilization was necessary. The negative effects, especially of amphotericin B, on the endothelium of porcine aortic valves have previously been investigated by Feng and associates. ${ }^{20}$ In our opinion, the sacrifice of an extra animal to receive a sterile allograft mitral valve was not justified for the purpose of this investigation. It can be suggested that the use of cryopreserved allografts should produce even better long-term results in an animal study. 


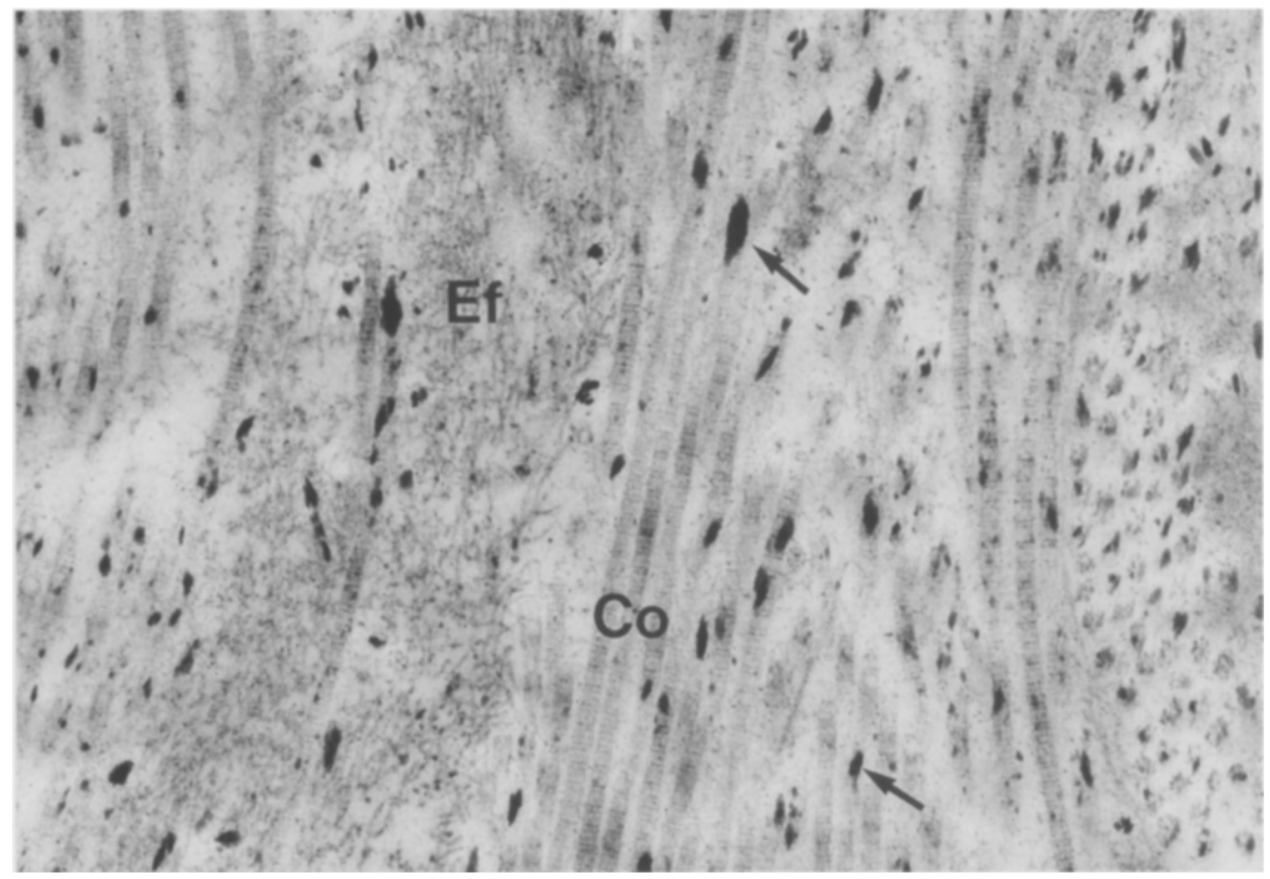

Fig. 7. Transmission electron micrograph of the anterior leaflet of an allograft mitral valve implanted for 132 days. Areas of organized collagen bundles (Co) and areas showing loose formations of elatic fibers (Ef) are present. The dark spots might represent the onset of calcification (arrow). (Original magnification $\times 33,000$.)

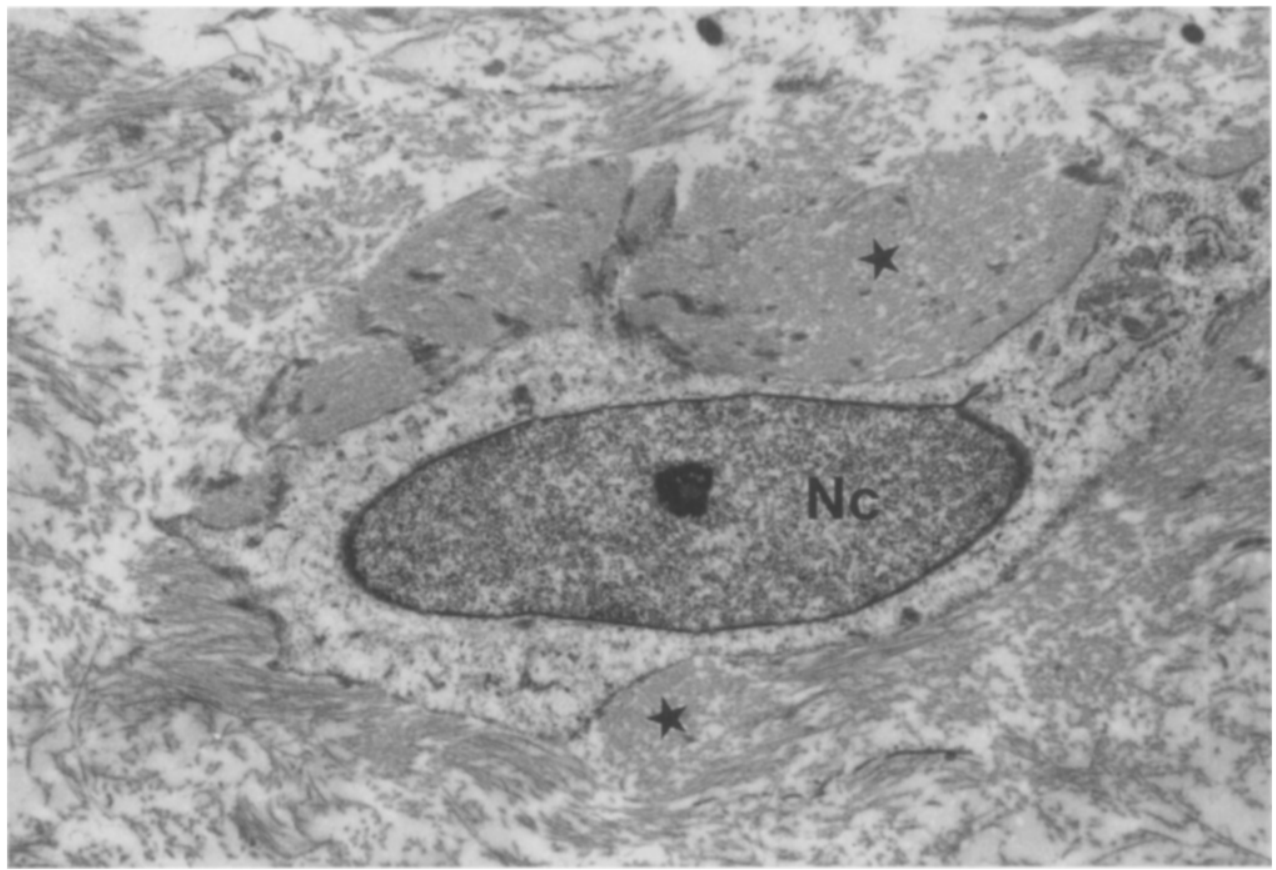

Fig. 8. Transmission electron micrograph of the anterior mitral leaflet from a specimen implanted for 158 days showing a fibroblast. A eucromatic nucleus $(N c)$ and the dense area of collagen fibrils (asterisks) around it could be a form of immature collagen suggesting cellular activity. (Original magnification $\times 5600$.) 
The hemodynamic performance of the stentless and chordally supported allograft mitral implant was very satisfactory at follow-up. The animals had normal hemodynamic function at rest. Transvalvular pressure gradients were not elevated if the valve was competent after implantation. A physiologic response to stress was observed during norepinephrine infusion. The effective orifice areas calculated during the hemodynamic study are rather low. This observation might be due to the formula because, to our knowledge, there are no data on body surface area in sheep. Therefore effective orifice area was calculated by means of a formula usually applied in human beings.

Echocardiographic examination revealed good movement of all valve components. In addition, in vitro studies of the stentless, chordally supported sheep mitral valve revealed significantly lower transvalvular gradients and significantly larger effective orifice areas than those of porcine bioprostheses of the same internal diameter. ${ }^{21}$

In summary, this experimental study confirms the possibility of mitral valve transplantation with good hemodynamic and echocardiographic valve characteristics. However, satisfactory long-term results can be expected only if the problem of a possible chordal rupture during a reparative phase of collageneous structures can be solved. Encouraged by excellent clinical results, the use of ePTFE suture for reinforcement of the natural chordae seems to be the most suitable approach.

We thank Professor K. Meßmer (Director, Institute for Surgical Research at Munich University) and Professor Robert W. M. Frater (Albert Einstein College of Medicine, Bronx, New York) for their generous support during the experimental phase. This work could not have been done without the technical skills of Astolfo Leon, Pablo Bon (now deceased), and Fred Wasserman. We thank Mrs. Scheler for preparing the specimens for electron microscopy.

\section{REFERENCES}

1. Hetzer R, Bougioukas G, Franz M, Borst HG. Mitral valve replacement with preservation of papillary muscles and chordae tendineae: revival of a seemingly forgotten concept. I. Preliminary clinical report. Thorac Cardiovasc Surg 1983;31:291-6.

2. Gams E, Hagl S, Heimisch W, Meisner H, Mendler N, Schad $\mathrm{H}$, Sebening F. Influence of papillary muscle function on the mitral valve and left ventricular mechanics. In: Vetter $\mathrm{HO}$, Hetzer R, Schmutzler H, eds. Ischemic mitral incompetence. New York: Springer-Verlag, 1991:35-48.

3. Bernhard A, Largiader F, Senning A. Homologe Mitralklappentransplantation. Langenbecks Arch Klin Chir 1967;319: 816-9.

4. Sievers HH, Lange PE, Yankah AC, Wessel A, Bernhard A.
Allogenous transplantation of the mitral valve: an open question. Thorac Cardiovase Surg 1985;33:227-9.

5. Vetter HO, Burack JH, Factor SM, Macaluso F, Frater RWM. Replacement of chordae tendineae of the mitral valve using the new expanded PTFE-suture in sheep. In: Bodnar E, Yacoub M, eds. Biological and bioprosthetic valves. New York: Yorke Medical Books, 1986:772-84.

6. Frater RWM, Vetter HO, Zussa C, Dahm M. Chordal replacement in mitral valve repair. Circulation 1990;82(Suppl):I125130.

7. David TE, Bos J, Rakowski H. Mitral valve repair by replacement of chordae tendineae with polytetrafluoroethylene sutures. J THORAC CARDIOvaSC SuRg 1991;101:495-501.

8. Zussa C, Polesel E, Da Col U, Galloni M, Valfré C. Seven-year experience with chordal replacement with expanded polytetrafluoroethylene in floppy mitral valve. J Thorac Cardiovasc Surg 1994;108:37-41.

9. Vetter HO, Dagge A, Liao K, et al. Mitral allograft with chordal support: echocardiographic evaluation in sheep. J Heart Valve Dis 1995;4:35-9.

10. Pomar JL, Mestres CA. Tricuspid valve replacement using a mitral homograft: surgical technique and initial results. J Heart Valve Dis 1993;2:125-8.

11. Acar C, Farge A, Ramsheyi A, et al. Mitral valve replacement using a cryopreserved mitral homograft. Ann Thorac Surg 1994;57:46-8.

12. Revuelta JM, Cagigas JC, Bernal JM, Val F, Rabasa JM, Lequerica MA. Partial replacement of mitral valve by homograft: an experimental study. J THORAC CARDIOVASC SURG 1992;104:1274-9.

13. Liao K, Wuu JJ, Frater RWM. Intraoperative epicardial echo/Doppler evaluation of a stentless, chordally supported quadricusp mitral bioprosthesis. ASAIO J 1993;39:M634-8.

14. Vrandecic M, Gontijo BF, Fantini FA, et al. Anatomically complete heterograft mitral valve substitute: surgical technique and immediate results. J Heart Valve Dis 1992;1:254-9.

15. Morea M, De Paulis R, Galloni M, Gastaldi L, di Summa M. Mitral valve replacement with the Biocor stentless mitral valve: early results. J Heart Valve Dis 1994;3:476-82.

16. Henney AM, Parker DJ, Davies MJ. Collagen biosynthesis in normal and abnormal human heart valves. Cardiovasc Res 1982;16:624-30.

17. Barnhart GR, Jones M, Ishihara T, Chavez AM, Rose DM, Ferrans VJ. Bioprosthetic valvular failure: clinical and pathological observations in an experimental animal model. J Thorac Cardiovasc Surg 1982;83:618-31.

18. Arbustini E, Jones M, Ferrans VJ. Formation of cartilage in bioprosthetic cardiac valves implanted in sheep: a morphologic study. Am J Cardiol 1983;52:632-6.

19. Vetter HO, Factor SM, Frater RWM. The use of glyceroltreated homologous pericardium as a substitute for cusps and chordae tendineae of the mitral valve in sheep. Thorac Cardiovasc Surg 1987;35:11-5.

20. Feng XJ, Hove CE, Mohan R, Walter PJ, Herman AG. Effects of different antibiotics on the endothelium of the porcine aortic valve. J Heart Valve Dis 1993;2:694-704.

21. Vetter HO, Erhorn A, Fontaine AA, Reichart B, Yoganathan AP. Hemodynamic and echocardiographic characteristics of a stentless allograft mitral prosthesis: an in vitro study. Cardiovase Surg [In press]. 